\title{
Strengthening of seismically deficient exterior beam-column connections using embedded steel bars
}

\author{
Ridwan ${ }^{1, *}$, Samir Dirar ${ }^{2}$, Yaser Jemaa ${ }^{3}$, Marios Theofanous ${ }^{2}$, and Mohammed Elshafie $^{4}$ \\ ${ }^{1}$ Department of Civil Engineering, Universitas Riau, Pekanbaru, Indonesia \\ ${ }^{2}$ Structural Engineering, University of Birmingham, Birmingham, United Kingdom \\ ${ }^{3}$ Civil Engineering, Liverpool John Moores University, Liverpool, United Kingdom \\ ${ }^{4}$ Construction Engineering, University of Cambridge, Cambridge, United Kingdom
}

\begin{abstract}
Several techniques for improving performance of reinforced concrete (RC) beam-column (BC) connections have been developed in last two decades, but these techniques have been criticized for being labourintensive and susceptible to premature de-bonding. To overcome these shortcomings, a novel technique utilising embedded steel bars has been developed in this study for strengthening seismically deficient RC BC connections. This technique involves drilling holes within the joint core. After the drilled holes are cleaned, they are partially filled with epoxy. Finally, steel bars are inserted in the epoxy-filled holes. Two exterior BC connections were constructed and loaded under displacement-controlled cyclic loading. The first specimen was a control specimen designed in accordance with the pre-1970s building codes to represent BC connections requiring strengthening. The second specimen was strengthened with eight $8 \mathrm{~mm}$ steel bars embedded within the concrete core in the joint area and epoxied to maintain the bond between the concrete and the steel bars. The strengthened specimen had superior performance compared to that of the control specimen in terms of joint shear stress, normalised principal tensile stress demand and stiffness degradation. The results show that shear stress of the joint was enhanced by about $8 \%$ whereas the enhancement in the principal tensile stress demand was $24 \%$ compared to that of the control specimen. The results showed that the proposed technique is capable in upgrading the seismic performance of seismically deficient RC BC connections.
\end{abstract}

\section{Introduction}

The connection between beam and column is a key role in preserving the performance of moment-resisting reinforced concrete (RC) frame structures to withstand lateral load. Inadequate designed joint, as can be seen in the buildings designed before the introduction of the principles of seismic design building codes, will experience concrete shear failure in the form of diagonal cracks in the joint region and bond failure of beam and or column

\footnotetext{
*Corresponding author: ridwan@eng.unri.ac.id
} 
reinforcement bars [1]. If the frame of the building has remained intact, many of the beamcolumn joints are distressed due to the missing of shear reinforcement in the joint area, and this jeopardizes the integrity of building [2].

Several approaches have been introduced to enhance the performance of seismically deficient $\mathrm{RC} \mathrm{BC}$ connections. The use of $\mathrm{RC}$ jackets as a technique in strengthening $\mathrm{RC}$ structures has been practiced for more than two decades. In this method, the strengthened elements of the structure were encased with high-strength concrete and then reinforced with transverse reinforcement. In some cases, longitudinal reinforcement bars of the beam element was extended around the joint regions to strengthen the column joint [3]. However, this technique has been criticized for being labour intensive and requiring complicated details during its application. Furthermore, the use of concrete jackets increases the dimension and self-weight of the structural elements and consequently alters the dynamic characteristic of the building [4]. To overcome these shortcomings, the deep embedment (DE) strengthening method was developed to increase the shear capacity of RC beams [5, 6]. The DE method proved to be effective in enhancing the shear capacity because this method relies on the concrete core to transfer stresses between the concrete and the embedded bar. Moreover, surface preparation and protection against fire and vandalism are not required. For the first time, this paper explores the application of the DE method to strengthen a seismically deficient exterior RC BC connection. In this study, steel bars were used as an embedded strengthening system.

\section{Experimental program}

\subsection{Specimens fabrication}

Two exterior RC BCJ specimens, namely BCJ-CS (unstrengthened control specimen) and BCJ-SS-S8 (strengthened specimen), were constructed to represent seismically deficient joints built according to the pre-1970s code provisions. The two specimens, which were designed to fail in shear, had the same dimensions and steel reinforcement configuration. Fig. 1(a) depicts reinforcing details for the test specimens. The upper and lower longitudinal beam reinforcement bars were hooked into the concrete core of the joint and extended for a distance of $195 \mathrm{~mm}(\sim 12 \mathrm{db}$ where $\mathrm{db}$ is the bar diameter) to provide anchorage and eliminate bond failure. Both specimens comprised one $8 \mathrm{~mm}$ horizontal closed stirrup in the joint area. The estimated flexural capacity of the beam was $72 \mathrm{kN}-\mathrm{m}$ for both positive and negative moment direction, whereas the flexural capacity of the column was $88.6 \mathrm{kN}-\mathrm{m}$ under a compressive axial load of $150 \mathrm{kN}$. This gives a column-tobeam flexural capacity ratio $(\mathrm{Mn}, \mathrm{c} / \mathrm{Mn}, \mathrm{b})$ of 1.23 and thereby avoid the strong beam-weak column condition. The nominal joint shear stress of the control specimen was 820 psi (equals to $5.6 \mathrm{MPa}$ ) which is higher than the allowable joint stress, $12 \mathrm{f}_{\mathrm{c}}$ ' ( $\mathrm{f}_{\mathrm{c}}$ ' in psi), ensuring the unstrengthened control specimen was deficient in shear [7]. The concrete cylinder compressive strength on the testing day was 31.3 and 24.9 MPa for the control and strengthened specimens respectively. Based on tensile tests, the yield strength, ultimate strength, and elastic modulus of the $8 \mathrm{~mm}$ and $16 \mathrm{~mm}$ reinforcement bars were $580 \mathrm{MPa}$, $672 \mathrm{MPa}$, and $198.7 \mathrm{GPa}$, and $512 \mathrm{MPa}, 671 \mathrm{MPa}$, and $200 \mathrm{GPa}$ respectively.

\subsection{Strengthening application}

The strengthening system comprised eight $8 \mathrm{~mm}$ diameter reinforcement steel bars. Before the concrete poured, the $10 \mathrm{~mm}$ acrylic rods were placed at the required positions within the joint cage area. The acrylic rods were removed from the concrete two days after casting. 
Before embedding the steel bars, the prepared holes were enlarged by using $12 \mathrm{~mm}$ drill bit and then the holes were cleaned by using compressed air to remove any residues. To maintain the bond between the embedded bars and the holes, the epoxy adhesive was used to fill two-thirds of the holes volume. A thin layer of adhesive was applied on to the surface of the embedded bar before inserted into the holes. Later, any excess epoxy was removed. The procedure explained above was used for simplicity as it did not require drilling holes.

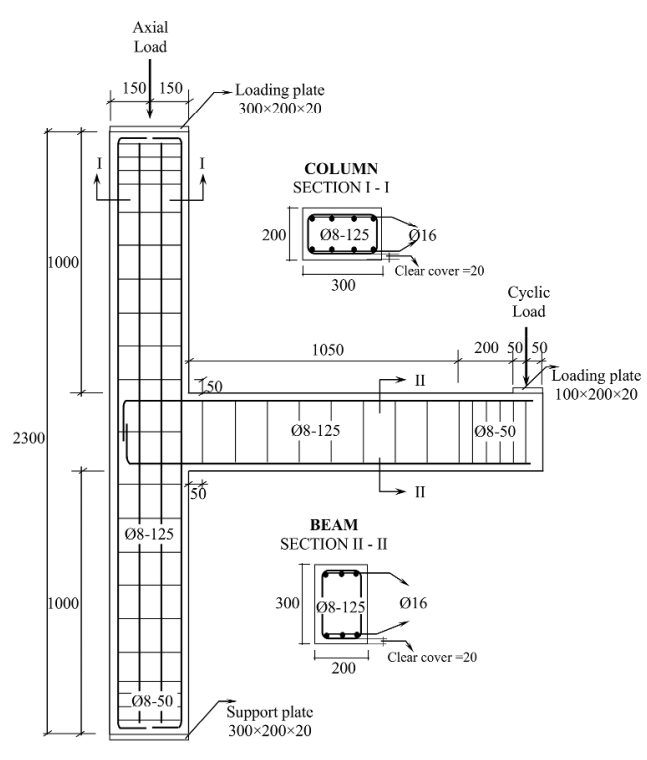

(a)

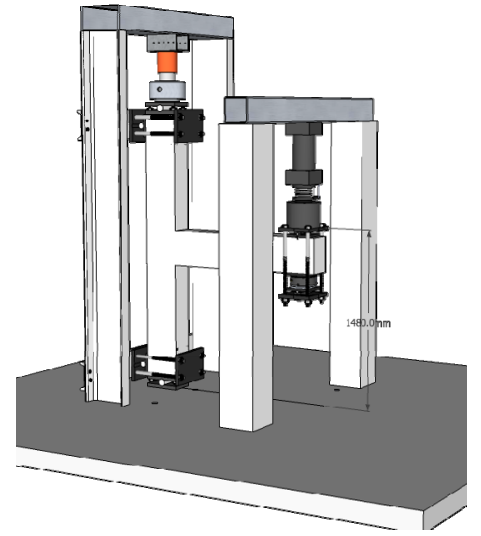

(b)

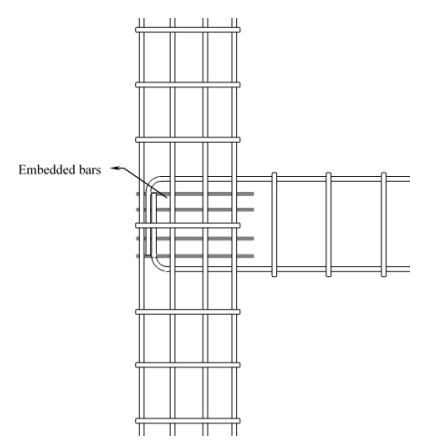

(c)

Fig. 1. The test specimens, units in mm: (a) Reinforcement details, (b) Test set up, (c) Embedded steel bars placed in the joint core.

\subsection{Testing arrangement}

The specimens were tested in the arrangement shown in Figure 1(b). The upper and lower column ends were supported laterally against a reaction frame which allowed in-plane rotations at both ends. A compressive axial load equals to $0.08 \mathrm{f}_{\mathrm{c}}, \mathrm{Ag}$ (where $\mathrm{f}_{\mathrm{c}}$, is the concrete cylinder compressive strength and $\mathrm{Ag}$ is the cross-sectional column area) was applied on the upper column end using a hydraulic jack. A displacement-controlled cyclic load, based on inter-story drift ratio, was applied at the beam tip using a $500 \mathrm{kN}$ hydraulic actuator with a stroke of $\pm 100 \mathrm{~mm}$. The advantage of this type of cyclic loading is that it allows examination of the joint shear behavior well after the development of joint shear cracks in both diagonal directions, but without significant deterioration in the joint strength due to severe cyclic loading. Two cycles were applied at the inter-story drift ratios of 
$0.04 \%, 0.10 \%, 0.25 \%, 0.35 \%, 0.50 \%, 0.75 \%, 1.00 \%, 1.50 \%, 2.00 \%, 3.00 \%, 4.00 \%, 5.00 \%$ and $6.00 \%$. The inter-story drift ratio is defined as:

$$
\text { drift ratio }=\frac{\delta}{L}
$$

where, $\delta$ is the vertical displacement of the beam-end, and $L$ is the distance from the loading point to the column face $(L=1300 \mathrm{~mm})$.

The instrumentation arrangements shown in Figures 1(b) were used to measure the load and displacement during the test. Two LVDTs were installed diagonally on the joint area to measure the joint shear deformation. The joint shear deformation $(\gamma)$ can be calculated from LVDT readings using the following equation:

$$
\gamma=\frac{\delta-\delta^{\prime}}{2 l} \times(\tan \alpha+\cot \alpha)
$$

where $\delta$ and $\delta^{\prime}$ are the LVDT readings where elongations have a positive sign, 1 is the initial distance between the mounting rods, and $\alpha$ is the initial inclination of the LVDTs to the horizontal or vertical.

\section{Results and discussion}

\subsection{Failure modes and joint shear strength}

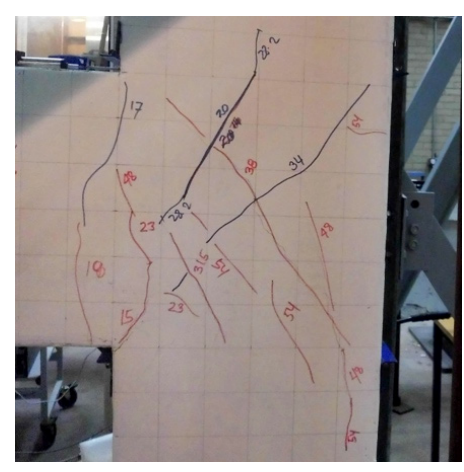

(a)

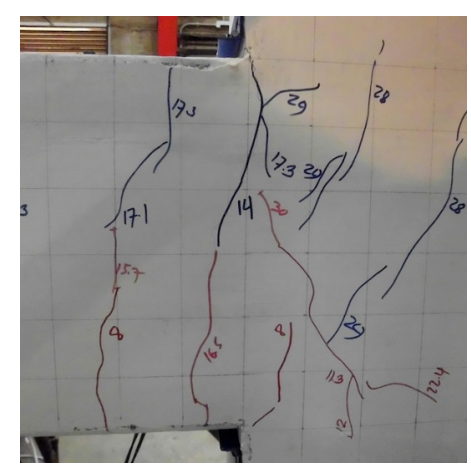

(b)

Fig. 2. Crack propagation at early stages of loading (a) control specimen, (b) strengthened specimen.

The crack development for both tested specimens is depicted in Fig. 2. The control specimen experienced a hybrid local damage and failure mechanism. This mechanism was characterized by shear failure in the joint area in the form of diagonal cracks. As a result, a wide concrete wedge evolved, leading to the spalling concrete cover of the column. Beyond a drift ratio of $3.00 \%$, severe damage to the concrete core resulted in a shear hinge mechanism, which is typical of joint shear (JS) failure. Compared to the control specimen, the strengthened specimen exhibited a more enhanced behavior where flexural cracks occurred in the beam region at early stages of loading, suggesting the outset of a beam hinge $(\mathrm{BH})$ mechanism. Between 1.00 and $2.00 \%$ drift ratio, diagonal cracks in the joint and in the beam were formed subsequently.

Nominal horizontal shear stress of the joint is evaluated using the following equation: 


$$
v_{j h}=\frac{V_{j h}}{w_{j} \times h_{c}}, V_{j h}=T_{b}-V_{c}
$$

where $V_{j h}=$ horizontal shear force acting across the joint region, $T_{b}=$ tensile force at the beam bars, $V_{c}=$ story column shear and $\mathrm{vjh}=$ horizontal shear stress.

Table 1 presents the significant contribution of the embedded steel bars on the shear strength of the tested specimens. A substantial improvement in the global performance of the strengthened joint can be seen in the joint shear stress capacity which both increased by about $7 \%$ and $8 \%$ for the case of upward and downward loading direction, respectively. At the local level, the shear deformation in the strengthened joint panel at upward drift ratios of $1.00 \%, 2.00 \%$ and $3.00 \%$ enhanced by about $98 \%, 29 \%$, and $17 \%$ respectively. There was no enhancement for the case of downward loading due to damage accumulation in the joint during upward loading, which preceded downward loading.

Table 1. Key response for tested specimens.

\begin{tabular}{|c|c|c|c|c|c|c|}
\hline Specimen & $\begin{array}{c}\text { Load } \\
\text { Direction }\end{array}$ & $\begin{array}{l}\mathbf{v}_{\mathbf{j h}}{ }^{(a)} \\
(\mathrm{MPa})\end{array}$ & $\begin{array}{c}\gamma_{1}^{(b)} \\
\left(\times 10^{-3} \text { radian }\right)\end{array}$ & $\begin{array}{c}\gamma_{2}{ }^{(c)} \\
\left(\times 10^{-3} \text { radian }\right)\end{array}$ & $\begin{array}{c}\gamma_{3}^{(\mathrm{d})} \\
\left(\times 10^{-3} \text { radian }\right)\end{array}$ & $\begin{array}{c}\text { Failure } \\
\text { mode }\end{array}$ \\
\hline \multirow{2}{*}{ BCJ-CS } & Upward & 5.14 & 0.653 & 2.216 & 4.206 & \multirow{2}{*}{ JS } \\
\hline & Downward & -4.69 & 0.245 & 1.473 & 3.993 & \\
\hline \multirow{2}{*}{ BCJ-SS-S8 } & Upward & 5.51 & 0.013 & 1.564 & 3.489 & \multirow{2}{*}{$\mathrm{BH}$} \\
\hline & Downward & -5.08 & 0.075 & 1.663 & 5.556 & \\
\hline
\end{tabular}

(a) Horizontal shear stress in the joint at peak load; (b), (c), (d) Joint shear deformation at 1.00, 2.00 and $3.00 \%$ drift ratio; (a) Calculated at the loading step corresponding to $20 \%$ reduction in ultimate load

A $22 \%$ (upward direction) and $24 \%$ (downward direction) increase in the normalized principal tensile stress demand of the strengthened specimen was observed compared to that of the control specimen. The variation of normalized principal tensile stress with joint shear deformation (see Fig. 3) shows that the strengthened specimen had higher joint stiffness for both loading directions. Beyond a downward drift ratio of about $3.00 \%$, the stiffness of the strengthened joint deteriorated due to excessive cracking. Post-test observation showed splitting cracks surrounding the embedded steel bars. This suggests a loss of bond between the concrete and embedded bars/epoxy.

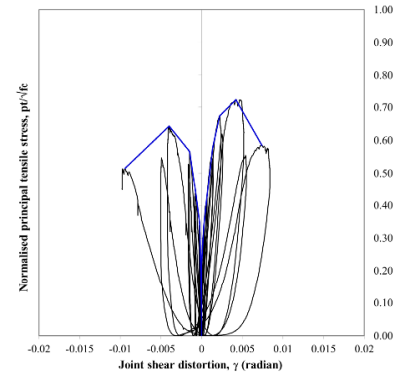

(a) Control specimen

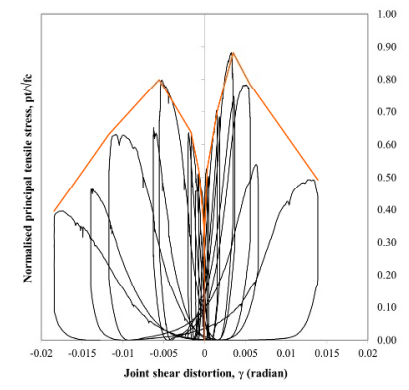

(b) Strengthened specimen

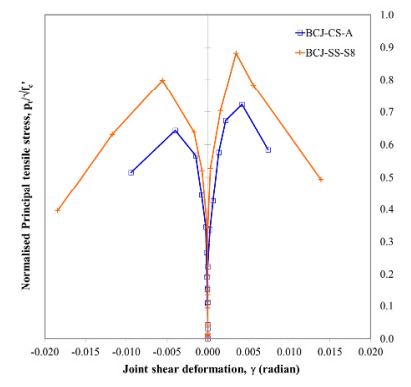

(c) Envelope curves

Fig. 3. Normalized principal tensile stress VS joint shear deformation. 


\subsection{Peak-to-peak stiffness}

The variation of the peak-to-peak stiffness of the specimen is presented in Fig. 4. In this study, the peak-to-peak stiffness is calculated as the gradient of the line connecting the peak of normalized load points in the normalized load-displacement curve attained at each drift ratio level. An examination of the stiffness degradation of the specimens reveals that the unstrengthened joint had higher stiffness degradation, varying from $30 \%$ at the initial load step to $3 \%$ at $1.00 \%$ drift ratio where joint cracks developed. Following shear cracking in the joint area at $1.50 \%$ drift ratio, the stiffness of both specimens reduced drastically due to excessive cracking.

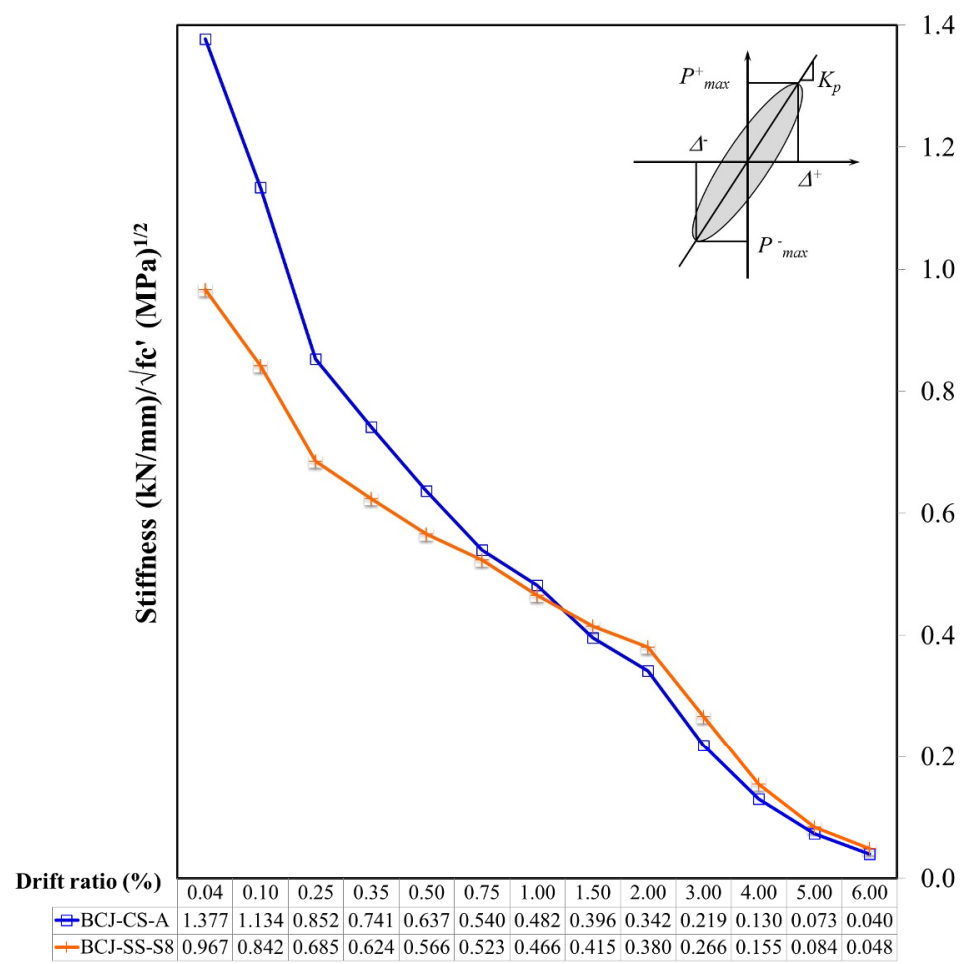

Fig. 4. Peak-to-peak lateral stiffness comparison.

\section{Conclusions}

This paper explores an innovative method to enhance seismically deficient RC BC connections. The results demonstrate the capability of the DE method in improving the seismic performance of shear strengthened RC BC connections. Based on the experimental results, the main findings of this study are: 1) The control specimen experienced shear failure in the joint area in the form of diagonal cracks whereas the strengthened specimen exhibited the more enhanced behavior where damage initially occurred in the beam region, and then diagonal cracks started propagating in the joint between 1.00 and $2.00 \%$ drift ratio. 2) The strengthened specimen showed superior global and local behavior compared to the control one. The shear stress in the joint area was enhanced by about $8 \%$ whereas the enhancement in the shear deformation between $1.00 \%$ and $3.00 \%$ drift ratios varied between $98 \%$ and $17 \%$. 3) The normalized principal tensile stress of the strengthened 
specimen increased by $22 \%$ and $24 \%$ compared to that of control specimen in the upward and downward loading direction, respectively. 4) The strengthened joint had lower stiffness degradation, varying from $30 \%$ at the initial load step to $3 \%$ at $1.50 \%$ drift ratio.

\section{References}

1. T. Paulay, M.J.N. Priestley, Seismic design of reinforced concrete and masonry buildings (John Wiley \& Sons, New Jersey, 1992)

2. U. Akguzel, Seismic performance of FRP retrifitted exterior $R C$ beam-column joints under varying axial and bidirectional loading (Thesis, University of Canterbury, Christchurch, 2011)

3. S.E. Dritsos Bulletin of the New Zealand Society for Earthquake Eng. 38 (2015)

4. C.G. Karayannis, C.E Chalioris, G.M. Sirkelis. Earthq. Eng. Struct. D. 37 (2008)

5. P. Valerio, T.J. Ibell, A.P. Darby, Proc. of the Institution of Civil Eng-Str B. 162 (2009)

6. O. Chaallal, A. Mofidi, B. Benmokrane, K. Neale J. Comp. Con. 15, 3 (2011)

7. M.R. Ehsani, J.K. Wight, J. of the American Concrete Institute 82, 2 (1985) 